\title{
Review of Principles of European Insurance Law
}

\section{Peter Hinchliffe}

Published online: 22 August 2008

(C) ERA 2008

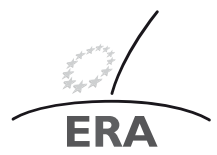

EUROPÄISCHE RECHTSAKADEMIE ACADEMY OF EUROPEAN LAW ACADEMIE DE DROIT EUROPEEN ACADEME DE DROT EUROPEEN TRIER - TREVES - TREVIRI

\section{Introduction}

In discussing the first draft of the PEICL (dated 17 December 2007) I will be commenting from the perspective of an Ombudsman from the United Kingdom. This means that my initial viewpoint is primarily derived from considering PEICL as an alternative to English or Scottish law in policies that are offered to consumers and to small and medium sized enterprises (SME) marketplaces. However, I also hope to comment on some other features and aspects based on my experience of commercial insurance and other EU jurisdictions.

The draft gives rise to a great many questions and comments and it is tempting to merely work through the various articles of the PEICL and to raise concerns or make further suggestions. However, given the limited time and the need for contributions to be made from a great many perspectives, I have endeavoured to concentrate on certain of the more significant issues that the draft has raised in my mind. I have tried to group these under three headings:

(1) What is not covered in PEICL that might have been.

(2) Concerns and questions about how PEICL could work in practice.

(3) Issues that might affect the adoption of PEICL in (a) the commercial/SME market and (b) the consumer market by consumers, insurers and intermediaries

Peter Hinchliffe $(\bowtie)$

The Financial Ombudsman Service

South Quay Plaza, 183 Marsh Wall

London E14 9SR, United Kingdom

e-mail: peter.hinchliffe@financial-ombudsman.org.uk

This paper is the written version of the presentation given by the author at the conference European Insurance Contract Law and the Common Frame of Reference (CFR), organised by ERA and the Joint Network on European Private Law in Trier on 21-22 January 2008. The author is Lead Ombudsman for Insurance, Financial Ombudsman Service, London. 


\section{What is not covered in the PEICL?}

I would like to raise a few issues that might have been addressed in the course of developing the content and considering the effect of the PEICL. It remains possible that some of these issues might usefully be addressed in the next draft:

\subsection{Fitness for purpose/Legitimate expectation/Implied terms}

What is missing from the present law in the UK in relation to insurance and from the PEICL is any real concept that there are essential elements to insurance contracts that consumers or SMEs can rely upon or safely assume will be in the contract when buying a certain type of policy. I have linked together some different legal concepts in my heading as they are all capable of providing some reassurance or support for consumers and to unsophisticated SME purchasers. In the commercial marketplace, including those SMEs who have access to advice from insurance brokers, the buyer can be expected to understand, either in detail or in broad terms the extent of the cover that they are gaining from the policy. However, where the insurance is being sold to consumers and small businesses, without the benefit of any advice, we need to consider whether it is appropriate for the law to impose a basic standard on the provider or seller as to the content of the insurance product that they are offering. Fitness for purpose, implied terms or warranties - the terminology may change can be difficult concepts to apply in insurance, however, consumers may well have an expectation as to what may be covered by motor insurance or travel insurance or buildings insurance. We know that consumers will seldom read the policy documents and that the sales process may not facilitate or permit this. Article 2:201 of the PEICL suggests that they may not even see all of the policy terms prior to the insurance cover commencing. Therefore how are they to understand what they are being offered or to make a choice between products with similar names being offered by insurers or intermediaries throughout the EU? In our work we will intervene in such issues. A travel policy which features a picture of a skier on the front cover as well as beaches and cafes etc, but has an exclusion for winter sports is likely to be found to have been misrepresented and therefore mis-sold in our view. An exclusion may not be given effect if it is plainly contrary to the reasonable expectation of any party who was induced to enter into the policy by misleading marketing documentation. But what about other examples? If we take travel insurance as an example; can a consumer rely in law on it having any particular characteristic or effect? Can insurers exclude all liability for medical expenses incurred overseas, all loss of possessions for which a carrier has not admitted liability, all liability if the policyholder consumes alcohol whilst travelling? I am aware of an attempt by a major credit card company to offer European wide travel insurance to its cardholders on a basis that was intended to escape regulation in the EU. They purported to make available to their customers the benefit of the travel cover that the credit card company itself held with an insurer based outside the EU. The consumer was granted the right to make a claim, on behalf of the credit card company, against the insurer for the consumer's own losses. However, only the credit card company could take legal proceedings. The overall effect of the policy was to purport to offer the insurance cover, but in fact the payment of any claim was within the discretion of the credit card company. Would this be acceptable 
under the PEICL? My experience of the Unfair Terms in Consumer Contracts Regulations has been that there is considerable nervousness in the insurance sector and also amongst lawyers and regulators about the idea that the law may have something to say about the extent of cover that should be offered under an insurance policy. However, without this safeguard the increase in choice that the PEICL might assist in offering to consumers and SMEs could be fraught with hidden dangers.

\subsection{Proportionality, reasonableness, good faith}

These terms may be implied in civil law countries into all contracts. They would not necessarily be implied in the United Kingdom. I am not yet clear if they are an effective feature of the Common Frame of Reference and would therefore be incorporated into the PEICL. My initial reading suggests that "good faith and fair dealing" would be. It would seem to be helpful if the PEICL could set out some underlying principles that might be expected to apply in the design, marketing and operation of insurance policies. Article 1:207 deals with non-discrimination and it is possible to see that other similar principles could be incorporated. This would be helpful in enabling the PEICL to be developed and to be applied to new insurance products and appropriate circumstances. To give one example from our work: A term in a travel policy that requires the policyholder to notify the insurer before having medical treatment at the insurer's expense sounds reasonable. However, applying this when the policyholder is unconscious due to a medical emergency seems wrong. It would be helpful if the legal principle that justifies these different conclusions could be expressed in the PEICL.

\subsection{How and when is agreement reached on the policy terms?}

Article 2:201 relates to the provision of pre-contractual documents. The list of information that must be provided has been specified, but it is not clear that the significant features of the policy cover needs to be included. We know the Unfair Terms in Consumer Contract Regulations state that the subject matter of the contract is not be subject to the rules on fairness provided its terms are plain and intelligible. Most insurers continue to regard that exception as meaning that the actual terms of cover, including the exclusions and limitations, are not to be judged by any particular standard of fairness. Sub paragraphs 2 and 3 of Article 2:201 suggests that even the provisions set out in Article 2:201 need not be provided in advance of the conclusion of the contract. If this is the case, how is the insured to agree to the contract terms? The PEICL states that contracts may be concluded in writing or orally. This is a mixed blessing for consumers and SMEs, who may well seek to rely on advice or guidance offered to them during the course of the sales process when this has created an expectation in their mind. They may however be horrified to discover that the limited documentation they did see could be modified by the insurer during the course of the sales process if they were notified verbally by the insurer or intermediary of some supplementary terms. I would suggest that the PEICL must include some more detailed provisions relating to the means by which the extent of cover and the key terms of the insurance policies are agreed and how both parties are placed in a position to understand and to accept or reject the obligations that they are entering into. 


\subsection{Multi benefit policies}

The annex to Article 1:103 seeks to break down forms of insurance cover into certain categories. These are then dealt with differently in the PEICL. However, it is a feature of policies in both the consumer and commercial marketplace that heads of cover will be combined in a single policy. The different benefits or heads of cover are then offered under a single contract. Under English law at present insurers have the right to avoid the whole of the policy and all heads of cover in the event of a breach relating to one area of cover, for example non-disclosure by the policyholder of a provision relating to one benefit, however minor. A single cheap and simple policy such as travel insurance may contain elements of the cover referred to in paragraphs 1, 2, 7, 9, 17, 18 and 19 of the Article. As marketing by insurance companies evolves, it is possible to see a simple household product for which will offer buildings, contents, legal expenses, and roadside assistance in the same policy. The PEICL needs to accommodate such.

\subsection{Other areas}

Other areas in which I think the PEICL might usefully be supplemented, would include:

(i) The consequences of failures by the parties to satisfy their obligations under the PEICL should be expressly stated. This has been done in most cases in the existing draft. However, in a number of circumstances it does not deal expressly with this, for example Articles 1:203, 1:204, 1:206, 2:102(4), 2:201 and elsewhere. Given the absence of recourse to national law the consequences may have to be clear in all instances.

(ii) The consequences of whatever may be finally included in respect of the legal status of brokers and intermediaries will need to be fully explored. I will return to this below.

\section{Some questions over how PEICL could work}

\subsection{The definition of insurance}

Article 1: 201 defines the insurance contract as "the contract under which one party, the insurer, promises another party, the policyholder, cover against a specified risk in exchange for a premium". The definition represents a commonsense approach to a difficult issue. However it may not be sufficient to avoid considerable uncertainty in practice as to what would constitute an insurance contract.

To take a simple example; again based on travel insurance, a policy may involve an insurer promising a consumer that in the event they are unable to travel by rail, sea or air then compensation will be payable to them. This may take the form of a simple cash payment or may include the cost of alternative travel. However, providers of travel services may also include in their standard terms with consumers a provision (frequently couched in the language of insurance) under which they will reimburse or cover the cost of alternative arrangements if the consumer is prevented from using the transport due to certain specified circumstances. An additional cost may be levied by the trans- 
port provider if this provision of the standard service contract is accepted by the consumer. It is not presently regarded as insurance but it could fall within this definition.

In similar circumstances transport providers such as airlines and rail companies will offer a range of tickets, the more expensive of which will provide an ability to change arrangements or seek a refund in the event that flights or trains are missed, whereas the cheaper ticket will not provide such a possibility. This is frequently the major and sometimes the only distinction between different priced tickets and they will be marketed on that basis. Is it also possible that such a premium priced ticket could fall within the ambit of the insurance contract as defined in the PEICL? At another extreme the definition would certainly include certain derivatives that are not presently regarded as insurance.

\subsection{Interpretation/uncertainty}

It is of course a common feature for those seeking to work across the EU that common law jurisdictions will be less comfortable with the broad phrasing and principles of legislation that may operate in civil law jurisdictions. The PEICL is, it appears to me, drafted with some broad phrasing and some statements of principle and intention that could come unstuck or create uncertainty in the course of its implementation. One example of this concern might be Article 12:101 which relies on the principle that the insured risk can exist or not exist and that a reasonable sum may be due to the insurer as a consequence and depending upon the circumstances. This provision raises the question of what constitutes the insured risk? For example, is it a ship that is insured or is it an illness against which a policyholder is insured? In the case of legal expenses insurance it is frequently required that the policyholder must have a reasonable prospect of success if a claim is to succeed. These prospects may at first appear reasonable and may subsequently change once further facts or evidence emerges. Similarly, in relation to the purchase of some commercial policies e.g. political and credit risk or directors and officers' liability cover, circumstances that may give rise to a claim may appear and disappear during the course of the insurance based upon perceptions or actions of third parties that may subsequently not be pursued. It is possible to understand the principle behind Article 12:101 and to apply it with commonsense and good intention. This would suggest that it is concerned with, for example, the ship that the insurer and insured believe that they are insuring, but which has in fact already sunk. However, the language employed here is similar in many respects to that in Article 4:201-203 and Article 4:301 where the concept of the risk insured is, I believe, to be given different effect. In these Articles the risk is something that is capable of aggravation or reduction and this is a concept that would work for the illness, or the directors and officers' liability cover, but would not appear to apply to a ship. I raise this here not to criticise the drafting, but to point out the practical difficulties that may arise or that may mischievously be created in seeking to apply PEICL.

\subsection{Consumer/SME/Commercial policies - can the law be the same?}

In the United Kingdom the underlying legal position is thought to remain largely the same in relation to commercial and consumer insurance contracts. However, regula- 
tion, operational practice and industry self regulation in the consumer and commercial marketplaces have diverged to such a significant extent that in practice two very different standards are applied to contractual issues and disputes affecting consumers rather than commercial policyholders. Regulation obviously has legal effect and the decisions of my organisation are also legally binding. The effect of these factors and, of course, the existence of EU legislation that is designed to protect consumers and which applies to insurance contracts, is that the overall legal position of policies with consumers is now different to that applying to policies with businesses. It appears to me to be unwise now to plan for the future on the basis that there will be common principles of insurance law that are equally applicable in relation to the commercial and consumer marketplaces. There are a number of ways in which contracts in these marketplaces might be distinguished in law, but I would suggest that we have to create a body of law that is capable of being operated fairly for both:

(i) An uninformed consumer with limited capacity to assess complex products and documentation, who has no access to useful impartial advice in selecting such products and who will not receive the full policy terms until after cover has commenced. Such a person may therefore not know how the product works until such time as a claim is made by him or her under the policy. The only dealings that such a consumer may have in concluding the policy may be with an intermediary (e.g. a bank) who may have created the policy, fixed the premium, prepared the marketing documentation and been responsible for the policyholder's disclosure to the insurer, but who is not party to the policy under which the claim is submitted; and

(ii) A very large commercial enterprise with access to sophisticated insurance and legal advice, with sole knowledge of the information that is relevant to the risk to be insured, and the ability to shop around between insurance providers and to propose terms and extract concessions from insurers based on its negotiating power.

Whilst underlying principles of contract law, agency law etc may well be consistent between the two sorts of transactions, in most respects I would suggest if would be helpful if the specific insurance legislation which is to be created dealt differently with the two classes of insurance transactions.

\subsection{The relationship with regulation}

There is already EU legislation in force that is relevant to insurance contracts, for example the Intermediation Directive and the Unfair Terms in Consumer Contract Regulations. It would be helpful if PEICL were to clarify how its terms related to those of existing EU legislation. However, even if this were to be done, any party seeking to utilise PEICL to extend its cross-border activities in the EU would then have to address the issue of the national regulation of insurance activities. It is not clear to me that either the UTCCR or the IMD, by way of example, are being interpreted consistently across the EU. It is certainly the case that national regulation is inconsistent. In these circumstances the PEICL might also need to clarify the extent to which it will override regulation if it is to be effective. However, the proposed means for incorporating PEICL is by the election of the parties, neither of whom can opt out of Regulation. For the policyholder this may not present a problem. They may 
choose to adopt PEICL in the knowledge that the regulation in the country in which they are resident will override it and that they understand the overall effect of the transaction they are entering into. However, for the insurer or intermediary seeking to market a product in a number of countries, it will still be necessary to take steps to assess the impact of offering the same policy terms in different countries and weigh up the effect of regulation on the marketing and operation of the policy.

\subsection{Role of Brokers and Intermediaries}

The provisions of Chapter 3 are admirably clear and, in my view, would provide a very good basis for law reform of consumer insurance in England and Wales and in Scotland! However, Articles 3:101 and 3:102 raise significant issues. By way of example, are all intermediaries and brokers to be regarded as insurance agents? How is the policyholder to know whether the agent is acting on behalf of the insurer or as an independent intermediary? What are the duties imposed on an independent intermediary by law? If the agent is independent why is the insurer liable for their breach? What is the scope of the agent's employment? How can the agent advise the policyholder if they act on behalf of the insurer? Who is responsible for the agent's advice to the policyholder? What knowledge is to be attributed to the insurance agent?

These provisions are revolutionary in terms of the laws of England and Scotland. This remains probably the most contentious part of insurance law reform in the UK. The notion that the broker is acting on behalf of the insurer is simply not accepted and, it has been argued, will be fatal to the commercial broking sector in the London market. In short, if the principle underlying Chapter 3 is to be pursued then a considerable amount of work will need to be done to explain its contractual implications for the three parties affected by it. If the role or responsibility of the agent is not addressed in the PEICL then this will introduce considerable uncertainty about the other provisions of the PEICL and how they operate. I note that the CFR deals with commercial agents in some detail and follows the line of existing EU legislation in this field. If insurance intermediaries are not to be regarded in law as commercial agents then we may need to clarify with equivalent detail the basis upon which the identity of their principal is to be decided and the relative responsibilities of the parties. It is important for us all to remember, in this context, that the position of the banking sector in the consumer insurance marketplace needs to be addressed. The banks have in some areas almost total control over the creation, terms, pricing and marketing of the insurance products. They merely "sub-contract" the underwriting to the lowest bidder. Nevertheless, the law in England has preserved the historic notion that they act as the agent of the either one side or the other and normally of the consumer. That notion plainly conflicts with the economic reality and it is questionable whether PEICL could be implemented without addressing such fundamental concerns.

\section{Issues that might affect the adoption of the PEICL in the commercial/SME marketplace}

There are significant disincentives for insurers who are used to working in English and Scottish law in adopting the PEICL. They are significantly worse off in relation to 
non-disclosure, duties to warn under Article 2:202 and 2:203, abusive clauses 2:304, prolongation Article 2:602, Chapter 3, Articles 4:201-203 and elsewhere. Against this it is difficult to see any real advantage in legal or contractual terms for an insurer who could offer a policy under English or Scottish law. However, it is likely that there will be marketing incentives for insurers who would like to sell to markets across the EU. Otherwise the radical change in the position of the insurer under a commercial insurance contract that is envisaged by the PEICL may well be a significant barrier to its adoption by insurers.

For commercial and SME customers the reverse is true. Nearly all the disadvantages for insurers are advantages for the policyholders and therefore the PEICL may well be attractive to them if it is to retain its existing content. It is therefore likely that the policyholders will have to drive its adoption in circumstances where English law and Scottish law might otherwise apply.

\section{Issues that might affect the adoption of the PEICL in the consumer market}

For UK insurers any consideration of this point must really await the outcome of UK law reform. It is likely that the PEICL will seem to offer a much more modest and reasonable change to insurers in the UK marketplace after law reform has taken place than it would do before. Nevertheless it is still worth remembering that the provisions in relation to the role of agents may still be bolder than those existing in local law. It is also worth noting that the provisions in relation to abusive clauses and the restatement of the UTCCR would provide a new challenge to insurers, who have successfully resisted or avoided what many believe were the intended effects of the UTCCR to date.

For UK consumers the PEICL would represent a considerable improvement in their legal position. However, consumers will have no ability to choose the PEICL as they will nearly always be dealing on the insurer's own terms. In practical terms there are other areas that need to be understood and assessed in considering whether the adoption of the PEICL will be beneficial to consumers. The consumer's main interest in the terms of an insurance policy will lie in its pricing and in whether or not a claim that they may expect to succeed, will succeed in practice. It will therefore be of real importance to them to understand what the detailed terms of cover are in the policy and whether these reflect their own expectation. If a product is to be marketed across EU boundaries then some of the detailed provisions of the policy detail will assume great importance if they are applied differently given the lifestyles and expectations of consumers in the national marketplace. For example if we were to look at a household insurance policy in the UK we might find that a provision that was relatively normal in Milan or Marseilles, e. g. that all ground floor windows should have shutters which should be secured at certain times, would be entirely unexpected in Manchester and would have serious consequences for the cover available to the policyholder. Similarly, there may well be provisions in relation to the insurance of goods, possessions, structures etc in gardens and outbuildings that may be normal in the UK marketplace but may look odd in other markets. In this context, it is a common feature of buildings insurance policies under English law at present that they will require details of any building 
that is not of a standard construction. Such a term would be difficult for insurers to use if it is applied across different jurisdictions. I am not suggesting that the PEICL needs to go into such a level of detail, however, some thought does need to be given as to how the detailed terms of the policies are to be either made known to and evaluated by consumers across different member states or some reassurance that their legitimate expectations of the policy will be made may be required. It seems to me important that the PEICL should not permit sellers of insurance to gain all the benefits from multi-national marketing on standard terms and leave all the detriment to buyers.

In considering the adoption of the PEICL in the consumer marketplace we must again consider the significant, if not controlling, role of intermediaries including banks, credit card suppliers, motor traders, travel agents etc in the design and marketing of insurance products. What does the PEICL mean for them? They may be the party that chooses the terms and the governing law even though they will not be a party to the policy when it is in force. In its present form the effect of Chapter 3 is probably sufficient to give all intermediaries an incentive to adopt the PEICL, particularly if it makes the insurer responsible to the insured for the agent's failures. However, I would suggest that this is not a sustainable feature of the PEICL.

\section{Conclusion}

It is difficult to approach the PEICL with anything other than admiration for those who have taken on the monumental and thankless task of attempting to understand and distil the variety of legal issues and legal provisions existing in European insurance law. My own past experience in leading and managing legal and commercial departments in a number of multi-national groups operating across Europe has led me to the conclusion that there is considerably greater similarity in the underlying principles of contract law in European states than the traditional split between common law and civil law might suggest. Provisions as various as "good faith" and "latent defects" have some resonance and effect in nearly all of the jurisdictions in which I have had experience. I am therefore optimistic that the work of the Restatement of European Insurance Contract Law Group will not only provoke debate but would also provide a platform from which European insurance law will develop. My comments about the first draft have inevitably focused on what concerns me or what I believe might hinder its utility. However, I hope that the work will continue and I firmly believe that greater knowledge of, and belief in the possibility of, an EU-wide framework of insurance contract law that could be given effect will serve to motivate insurers, national legislators and regulators to ensure that their own contract terms and law are within the acceptable mainstream of educated legal opinion. Sadly, at present I suspect that English insurance law will not find itself in that position. 